\title{
Statins in Females
}

\author{
Vanajakshamma Velam ${ }^{1} \quad$ Latheef Kasala $^{1} \quad$ Narendra Chanda ${ }^{1}$ \\ ${ }^{1}$ Department of Cardiology, Sri Venkateswara Institute of Medical \\ Sciences (SVIMS), Tirupati, Andhra Pradesh, India \\ Address for correspondence Vanajakshamma Velam, MD, \\ DM, Department of Cardiology, Sri Venkateswara Institute \\ of Medical Sciences, Tirupati 517507, Andhra Pradesh, India \\ (e-mail: vvanaja1966@yahoo.in).
}

Ind J Car Dis Wom 2019;00:99-106

\begin{abstract}
Keywords

- statins

- female

- cardiovascular disease

- prevention

Statins have turned out to be widely recommended in the prevention of cardiovascular diseases (CVD) owing to their favorable effect on lipid metabolism and patient survival. Statin treatment is usually all around endured and effective in the prevention and treatment of CVD, irrespective of cholesterol levels. However, studies on statin therapy have reported various adverse effects such as myalgia, myopathy, rhabdomyolysis, and diabetes mellitus. Primary and secondary prevention studies of CVD have been grossly underpowered regarding enrolment of women, limiting the ability to stratify results by sex. In high-risk women, statins reduce coronary events and stroke. For primary prevention, the benefits and risks of statin therapy remain less well defined in women. CVD prevention includes lifestyle modification for all women and medical treatment for those with prevailing CVD risk factors or known disease. It has been proved that statins reduce the rates of cardiovascular events and mortality. Randomized clinical trials suggest that statins are safe in most patients with the previous stroke and reduces the occurrence of coronary adverse events and stroke by $\sim 20 \%$. In populations at high baseline risk of CVD, cardiovascular benefits of statin therapy overweigh the potential risk of increased serum glucose levels.
\end{abstract}

\section{Introduction}

Cardiovascular disease (CVD) remains the second leading cause (19.9\%) of death in Asia-Pacific women after cancers (26.6\%). ${ }^{1}$

Statins (HMG-CoA reductase inhibitors) diminish the burden of atherogenic lipoprotein in serum. ${ }^{2}$ Statins are the basis for lipid-lowering treatment worldwide in cardiovascular (CV) pharmacotherapy ${ }^{3}$ in patients with dyslipidemia, ${ }^{4}$ coronary artery disease (CAD), stroke, diabetes mellitus (DM), hypertension, and chronic kidney disease (CKD). ${ }^{5}$ It has attributed the decrease in the incidence of $\mathrm{CV}$ mortality worldwide to prevent CAD and total CVD by lowering of cholesterol. ${ }^{6}$

The beneficial role of statins is most intensively studied in both primary and secondary prevention. ${ }^{7-9} \mathrm{~A}$ study done by Cholesterol Treatment Trialists' (CTT) Collaboration showed a $21 \%$ decrease in CVD mortality and morbidity, a $12 \%$ reduction in all-cause mortality by lowering $1.0 \mathrm{mmol} / \mathrm{L}$ low-density lipoprotein cholesterol (LDL-C). ${ }^{10,11}$
Statins are safe and well endured, but all patients cannot use statins due to their intolerance. Muscle-related adverse events are most frequently attributed with statin intolerance. ${ }^{12,13}$ Even among patients with CVD, statin discontinuation rates remain high. ${ }^{14,15}$ There is a strong correlation of statin nonadherence with acute CV event risk and increasing the risk for recurrent MI and CVD. ${ }^{16}$

In high-risk women, statins reduce coronary events and stroke by $\sim 20 \%,{ }^{10}$ but $>50 \%$ of the CV events occur in low-risk women. In women, the benefits and risks of statin therapy for primary prevention remain less well defined. Primary prevention studies have shown that statin treatment lowers the rate of cardiovascular events by $\sim 20 \%$, the study populations predominantly included men; hence, questions remain about the safety and efficacy of statins to prevent CVD in women. In secondary prevention settings, statins reduce risk of recurrent CVD events and CVD mortality, with benefits of comparable magnitude in men and women. ${ }^{17}$
(C)2019 Women in Cardiology and Related Sciences
License terms

$($ () (1) $\odot \circledast$ 


\section{Risk of CVD in Men and Women}

CVD is the foremost killer of both men and women. Women develop CAD at an older age (usually $\sim 10$ years later) than men. By then, women may already have coexisting CV risks such as diabetes and high blood pressure. Women are more likely to have coronary microvascular disease than men. This damage is harder to detect early with standard tests and may delay treatment that can help reduce related symptoms.

The 2013 ACC/AHA guidelines are the first to encompass identification of candidates using a CVD risk calculator that takes sex into account, recommend statin therapy for four specific patient populations ${ }^{7}$ :

1. With established CVD.

2. With LDL-C $\geq 190 \mathrm{mg} / \mathrm{dL}$.

3. Aged between 40 and 75 years with type 1 or type 2 diabetes mellitus and LDL-C 70 to $189 \mathrm{mg} / \mathrm{dL}$.

4. Aged between 40 and 75 years with LDL-C 70 to $189 \mathrm{mg} / \mathrm{dL}$ and 10 -year risk for CVD $\geq 7.5 \%$.

This risk calculator uses a formula that estimates 10 years and lifetime atherosclerotic cardiovascular disease (ASCVD) risk, defined as risk for first nonfatal MI, death due to coronary heart disease (CHD), and stroke. ${ }^{18}$ The calculation considers age, sex, race, a habit of smoking, DM, blood pressure, treatment for hypertension, total and high-density lipoprotein cholesterol (HDL-C).

The purpose of risk assessment is to identify higher-risk individuals for primary prevention. The guidelines first recommend lifestyle changes including diet, exercise, and weight loss for CVD primary prevention before starting statin therapy. Family history of premature CVD, hsCRP levels, coronary artery calcium score, and ankle-brachial index can be considered as additional parameters for the assessment of 10 -year risk between $5 \%$ and $7.5 \%$.

\section{Novel Risk Factors of CVD in Women}

Traditional risk factors may underestimate the risk in women. Novel risk factors that may improve the risk detection are ${ }^{19,20}$ the following:

1. Abdominal obesity.

2. Metabolic syndrome.

3. Depression.

4. Low estrogen levels.

5. Elevated C-reactive protein (CRP).

6. Elevated levels of testosterone.

7. Polycystic ovary syndrome (PCOS).

Randomized clinical trials (RCTs) of statins with metabolic syndrome (MetS) patients showed benefits on LDL-C, measures of endothelial function and inflammation, especially in lowering hsCRP, and subsequent contribution in reduction of CV events in patients with MetS. ${ }^{21}$

Depression is a common problem associated with many chronic medical conditions such as CAD, hypertension, and diabetes. Statins provide protection against coronary and cerebrovascular diseases by decreasing cholesterol synthesis in the liver. Statins also have potential anti-inflammatory activity. Since the pathophysiology of depression involves inflammation, statins could have a role in the treatment of mood disorders and might become a pharmacotherapy option for patients experiencing depression. ${ }^{22}$

Statins improve clinical, metabolic, and endocrine profiles of PCOS women. Despite an overall favorable risk profile, use of statins in reproductive-age women should be recommended with caution due to their potential teratogenic effects. ${ }^{23}$

Statins may function by lowering testosterone. In a study with 368 young women with PCOS, statins lowered testosterone by $-0.40 \mathrm{nmol} / \mathrm{L}$. Overall statins lowered testosterone by $-0.44 \mathrm{nmol} / \mathrm{L}^{24}$

\section{Statins}

Due to their beneficial effect on lipid and lipoprotein metabolism, statins have become extensively prescribed in the primary and secondary prevention of CVD. ${ }^{17}$

Statins help to prevent CAD in patients without CVD history (primary prevention) and in patients who are at high risk of developing CVD or have had a CVD and cerebrovascular accident (CVA) (secondary prevention).

A reduction of 20 to $44 \%$ in cardiac events after the initiation of statin therapy was reported with equivalent cardioprotective advantages in both the genders. ${ }^{17,25,26}$ The safety concerns regarding statins are important in women. The most common side effect of statin therapy is myalgia, which has reported in $20 \%$ of women and is a major cause of intolerance and discontinuation. ${ }^{27}$ Statins may be teratogenic and should be avoided in pregnant women and women who are planning to become pregnant. The FDA recognizes that while liver injury is a rare side effect of statin therapy, FDA has recommended to check liver enzymes before starting statin therapy or if symptoms of liver damage emerge. Statins are associated with $12 \%$ increased risk for developing elevated blood sugar or diabetes. ${ }^{28}$ FDA has also reported rare cases of nonsevere cognitive impairment.

\section{Mechanism of Action}

Statins inhibit the rate-limiting enzyme of the hepatic cholesterol synthetic pathway HMG-CoA reductase, which converts HMG-CoA to mevalonic acid (a precursor in the de novo biosynthetic pathway of cholesterol). Statins inhibit HMG-CoA reductase function through competitive inhibition which leads to decreased cholesterol production (-Fig. 1). ${ }^{29}$

\section{Objectives of Statin Therapy}

Landmark trials have supported the statin therapy for preventing the onset and progression of ASCVD. ${ }^{30,31}$ It has been established that the development of ASCVD is associated with elevated levels of LDL-C, and the overall incidence and prevalence of mortalities associated with ASCVD can be reduced by lowering LDL-C levels through statins. In high-risk patients, statins are used in primary prevention to maintain normal levels of LDL-C, whereas statins are used to reduce the risk 


\section{De novo Cholesterol Synthesis}

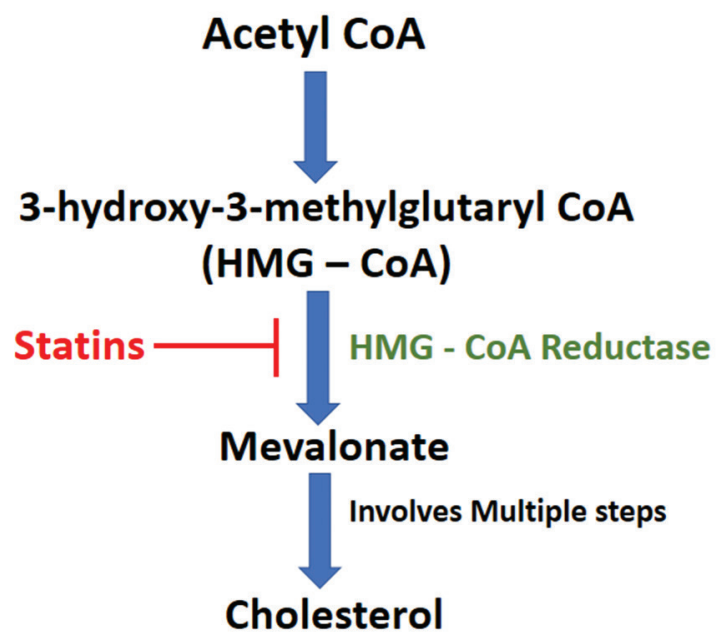

Fig. 1 Mechanism of action of statins.

of CV events by lowering LDL-C levels in ASCVD confirmed patients. Statins have pleiotropic effects on multiple sclerosis, rheumatoid arthritis, strokes, systemic lupus erythematosus, inflammatory bowel diseases, cancer, chronic pulmonary obstructive pulmonary disease, Parkinson's disease, Alzheimer's disease, and HIV and bacterial infections. ${ }^{32}$

\section{Primary Prevention of CVD}

In women, the effect of statin therapy is less clear in primary prevention. The primary prevention of CVD in women ought to incorporate therapeutic lifestyle changes which can benefit the controlling of physical inactivity and obesity. ${ }^{33}$

CVD primary prevention trials have been grossly underpowered regarding enrolment of women, limiting the ability to stratify results by sex. This lack of adequate data has interpreted as a lack of statin efficacy for primary prevention in women. However, a large meta-analysis of 22 statin therapy trials with $>174,000$ participants ( $27 \%$ women) showed that statin therapy has similar effectiveness for preventing both primary and secondary major CV events and CV-related mortality in women and men. ${ }^{30}$ The results showed that for every $1 \mathrm{mmol} / \mathrm{L}(18 \mathrm{mg} / \mathrm{dL})$ reduction of LDL-C, the CV events in women were $15 \%$ reduced in primary prevention. Among women with a 5 -year risk $<10 \%$ statin therapy lowered risk by $26 \%{ }^{34}$

JUPITER (Justification for the Use of Statins in Prevention) study, ${ }^{35}$ an interventional primary prevention trial with rosuvastatin, enrolled 17,802 study participants in which $38 \%$ were women. This trial tested the efficacy of statin therapy in individuals with low LDL-C $(<130 \mathrm{mg} / \mathrm{dL}$ ) levels but elevated $(\geq 2 \mathrm{mg} / \mathrm{dL})$ high-sensitivity C-reactive protein (hsCRP). Statin therapy prevented some $\mathrm{CV}$ events in women; the 5 -year number needed to treat to prevent a major CV event was 31 and 17 for women versus men, respectively, reflecting the lower baseline risk. ${ }^{35}$

The CV and mortality advantages of statin treatment surpassed the diabetes hazard, even in those at higher risk for developing diabetes. For a long-term follow-up period of 5 years, $86 \mathrm{CV}$ events/deaths were avoided, with no incident of new-onset diabetes (NOD) in patients with no significant diabetes risk factors. In patients diagnosed to have at least one factor for diabetes development, $93 \mathrm{CV}$ events or deaths were avoided for each 54 NOD cases. Statin treatment was linked with time to NOD of just 5.4 weeks compared with placebo. ${ }^{36}$ While getting statin treatment, and patients ought to be encouraged to practice physical activity, reduce caloric intake, get more fit by losing weight, and smoking cessation to reduce the risk of NOD.

In patients with NOD, it is recommended to continue statin therapy and advised the management of these patients with hypoglycemic diet, loss of weight, and administration of antidiabetic drugs, if required. ${ }^{37}$ When nonpharmacological therapy is not effective in primary prevention of overweight or obese patients, the lipid-lowering approach is to introduce statins after the careful estimation of CV risk. ${ }^{38}$ There was a significant $20 \%$ reduction in total mortality (mortality benefits are equal in both the genders). This is further confirmed by a statin primary prevention meta-analysis in women where a $37 \%$ reduction in mortality was observed (relative risk [RR]: 0.63; $P<0.001)^{39}$

A meta-analysis (sex-specific) by Bukkapatnam and associates $^{40}$ comprising 6 primary prevention trials, reported $144 \mathrm{mg} / \mathrm{dL}$ baseline LDL-C levels was found with a significant decrease in CHD in women, but not with all-cause mortality (RR: 0.780 .90 , respectively). In another meta-analysis comprising both primary and secondary prevention trials, statin therapy was benefited in women for prevention of primary events, but substantial advantage was observed in the lowest risk category (odds ratio [OR]: 0.59 for low risk; OR: 0.75 for medium risk; and OR: 0.88 for high risk). ${ }^{41}$

In a meta-analysis conducted by CTT Collaborations in patients with secondary and high-risk primary prevention, the CV risk reductions were $17 \%$ and $22 \%$ in women and men, respectively. ${ }^{11}$ In another meta-analysis in which the outcome was measured with the effects per $1.0 \mathrm{mmol} / \mathrm{L}$ (38 $\mathrm{mg} / \mathrm{dL}$ ) reduction in LDL-C, results showed that the proportional declines in LDL-C were similar for women and men (RR: 0.84 vs. RR: $0.78, p=0.33$ ). ${ }^{10,26}$

Results of a meta-analysis of low-risk primary prevention of both the genders at $<10 \%$ predicted 10 -year risk, showed insignificant differences in proportional reductions by gender $(p=0.11)$. A significant reduction in total mortality was observed in both the genders with statin therapy. The study concluded that the statin therapy provides similar benefits in both the genders at the same risk of CVD. ${ }^{34}$ Because of their capability to cause birth defects statins are contraindicated in women during pregnancy; otherwise they are safe in men and women for long-term use. ${ }^{42}$ Trials on statins comparing primary events in men and women are summarized in - Table 1 .

\section{Secondary Prevention of CVD}

Although women are under-represented with $<20 \%$ of total participants in secondary prevention trials, reports of major 
Table 1 Summary of major clinical trials on statins

\begin{tabular}{|l|l|l|l|l|l|l|}
\hline Study & $\begin{array}{l}\text { Primary/Secondary } \\
\text { prevention }\end{array}$ & Drug & Control & $\begin{array}{l}\text { Follow-up } \\
\text { (months) }\end{array}$ & $\begin{array}{l}\text { Primary } \\
\text { events in } \\
\text { men/total }\end{array}$ & $\begin{array}{l}\text { Primary events } \\
\text { in women/total }\end{array}$ \\
\hline ASCOT-LLA & Primary prevention & Atorvastatin & Placebo & 40 & $81 / 4,189$ & $19 / 979$ \\
\hline HPS & Primary prevention & Simvastatin & Placebo & 60 & $1,666 / 7,727$ & $367 / 2,542$ \\
\hline JUPITAR & Primary prevention & Rosuvastatin & Placebo & 22.8 & $103 / 5,475$ & $39 / 3,426$ \\
\hline A to Z & Secondary prevention & Simvastatin & Simvastatin & 24 & $239 / 1,716$ & $91 / 549$ \\
\hline PROSPER & Primary prevention & Pravastatin & Placebo & 38.4 & $222 / 1,396$ & $186 / 1,495$ \\
\hline PROVE-IT & Secondary prevention & Atorvastatin & Pravastatin & 24 & $376 / 1,634$ & $94 / 465$ \\
\hline TNT & Secondary prevention & Atorvastatin & Atorvastatin & 58.8 & $1,113 / 4,054$ & $292 / 941$ \\
\hline SEARCH & Secondary prevention & Simvastatin & Simvastatin & 80.4 & $1,277 / 5,005$ & $200 / 1,026$ \\
\hline
\end{tabular}

studies support the prescription of statins in either genders with established CVD. A meta-analysis with secondary prevention trials provided gender-based analysis, which presumed that statin treatment had decreased the risk of CVD equally in both women and men (corresponding relative risks [RRs] are 0.81 and 0.82 , respectively). ${ }^{17}$ Some of the studies concluded that statins reduced the risk of stroke and allcause mortality only in men but not in women, which is due to less statistical power in women in those studies.

In PROVE IT-TIMI 22 trial (Pravastatin or Atorvastatin Evaluation and Infection Therapy-Thrombolysis in Myocardial Infarction 22), ${ }^{43}$ investigators evaluated the outcome of the lipid-lowering capacity of pravastatin $40 \mathrm{mg}$ (standard) after acute coronary syndromes (ACS) with atorvastatin $80 \mathrm{mg}$ (intensive therapy) for two years. Women in intensive statin therapy group had more reduction in CV events and mortality. Women had benefited with statin therapy for secondary prevention.

After ACS, women randomized to high-dose statin therapy (80 $\mathrm{mg}$ atorvastatin daily) versus standard therapy (20 mg pravastatin daily) experienced a $25 \%$ reduction in CVD events and mortality. ${ }^{43}$ Two separate meta-analyses have also reported similar findings. The first included 11,000 women from 11 secondary prevention trials and found that statin therapy reduces CVD risk by $19 \%$; the other included $>40,000$ women from 18 trials and found clear benefit for both CVD (OR: 0.78) and stroke (OR: 0.74). ${ }^{17,41}$

\section{Risks and Adverse Effects of Statins}

Adverse effects with statins are not common, occurring only in up to $3 \%$ of individuals in RCTs on statins and most are not serious. The common adverse effects of statins are the following:

- Muscle related side effects:

- Myalgia or soreness or aching without associated injury (1.5-3.5\%).

- Myopathy or muscle soreness associated with muscle injury.

- Rhabdomyolysis (occurs in 5 of every 10,000 statins users).

- Liver abnormalities ( $<1 \%$ of people taking statins).
- Diabetes.

- Gastrointestinal symptoms such as constipation, nausea, or indigestion.

- Headache.

- Cognitive impairment.

The most commonly reported adverse effects of statins in most of the RCTs are statin-associated muscle symptoms (SAMS). ${ }^{44,45}$ SAMS are the very common reason for the discontinuation of statin treatment regardless of the notable $\mathrm{CV}$ benefits. ${ }^{45,46}$

SAMS include myalgia, cramps, and weakness. The incidence of SAMS ranges from 10 to $29 \%$ in patients on statin therapy, the incidence of rhabdomyolysis and myopathy with elevated plasma creatine kinase are very rare. ${ }^{47}$

A clinical myalgia scoring system called Statin Myalgia Clinical Index (SMCI) was proposed by the National Lipid Association (NLA) and is useful in deciding the likelihood that the muscle symptoms are statin-related. ${ }^{47}$ PRIMO $^{44}$ and $\mathrm{STOMP}^{48}$ are studies that are related to SMCI.

High doses and increased serum concentration of statins, use of statin-interacting drugs which can hinder statin catabolism, hypothyroidism, decreased muscle mass, and increased physical activity can boost the risk of SAMS..$^{44,49,50}$ In addition, elderly age, female gender, physical weakness, and alcohol use can also likewise expand the hazard of SAMS. ${ }^{50}$ Azole antifungals and macrolide antibiotics, which are metabolized by CYP3A4, protease inhibitors, $\mathrm{Ca}^{2+}$ channel blockers, and warfarin can rise the serum concentrations of statins. ${ }^{51}$

ASCOT-LLA study ${ }^{52,53}$ (Anglo-Scandinavian Cardiac Outcomes Trial-Lipid-Lowering Arm) evaluated numerous adverse effects of statins. The study findings revealed the rate of muscle-related events in the blinded phase as $2.0 \%$ and $2.03 \%$ in placebo and statin groups, respectively. Whereas in unblinded phase, the rate of muscle-related events was found $1.00 \%$ and $1.26 \%$ in placebo and statin groups, respectively. Statin therapy may cause raised blood glucose and risk of diabetes mellitus, which is supported by a meta-analysis in which a $12 \%$ increased diabetes risk was found. ${ }^{28}$ The American Heart Association (AHA) and the American Diabetes Association (ADA) have affirmed, however, that the cardiovascular benefits of statin therapy overweigh the potential risk of developing diabetes. 
Table 2 Benefits and adverse effects of statin therapy

\begin{tabular}{|c|c|}
\hline Benefits & Adverse effects \\
\hline $\begin{array}{l}\downarrow \text { Risk of total and ischemic stroke ( } 16 \% \text { and } 21 \% \text {, } \\
\text { respectively). } \\
\downarrow \text { Risk of nonfatal MI and CHD death ( } 27 \% \text { and } \\
20 \% \text {, respectively). } \\
\downarrow \text { Risk of revascularization procedures }(25 \%) \text {. }\end{array}$ & $\begin{array}{l}\text { - } \text { No evidence of Cognitive dysfunction. } \\
\text { - Small increase in risk of hemorrhagic stroke in individuals with } \\
\text { - } \text { Clinically insignificant elevation of liver enzymes. } \\
\text { - Incidence of liver failure: } 1 / 100,000 \text {. } \\
\text { - } 0.1 \% \text { incidence of NOD with moderate-intensity statin therapy. } \\
\text { - } 0.2 \% \text { incidence of NOD with high-intensity statin therapy. } \\
\text { - Incidence of SAMS are } 10-29 \% \text { and } 1-2 \% \text { in observational studies and } \\
\text { in RCTs, respectively. } \\
\text { - Incidence of myopathy is } 1 / 1,000 \text {. } \\
\text { - Incidence of rhabdomyolysis is } 1 / 10,000 \text {. }\end{array}$ \\
\hline
\end{tabular}

Abbreviations: CHD, coronary heart disease; MI, myocardial infarction; NOD, new-onset diabetes mellitus; RCT, randomized controlled trial; SAMS, statin-associated muscle symptoms.

\section{Statin Intolerance}

Statin intolerance is defined as a failure to endure at least two different statins, with one statin assessed at its lowest effective dose. ${ }^{54,55}$ The most common cause of statin intolerance is SAMS. Benefits and potential adverse effects of statin therapy are explained in - Table 2 . $^{56}$

IMPROVE-IT ${ }^{57}$ (Improved Reduction of Outcomes: Vytorin Efficacy International Trial) demonstrated that the combination of statin therapy (ezetimibe + simvastatin) did not increase the incidence of SAMS compared with simvastatin alone. ${ }^{53}$ In patients with statin intolerance, studies have recommended that PCSK9 inhibitors can be used safely in those patients. ${ }^{58-60}$

Diabetes mellitus: It has been evidenced by JUPITER study ${ }^{26}$ that the relative risk of NOD was significantly increased by $25 \%$ with rosuvastatin (20 mg daily dose) when compared with placebo. Even in patients at high risk of developing diabetes the cardiovascular and mortality benefits exceeded the risk of diabetes. ${ }^{36}$

When compared between more-intensive and less-intensive statin therapies, a significantly higher risk of NOD was associated with more-intensive statin therapy. This finding was proven by the TNT (Treating to New Targets), ${ }^{61}$ IDEAL (Initiating Dialysis Early and Late), ${ }^{62}$ PROVE-IT TIMI, ${ }^{63}$ A to Z, ${ }^{64}$ and SEARCH (Study of the Effectiveness of Additional Reductions in Cholesterol and Homocysteine $)^{65}$ studies.

Liver considerations: As the statin metabolism uses cytochrome P450 pathway in the liver, it has been assumed that they have potential hepatotoxicity. Hepatologists use Hy's law to determine drug-induced liver injury. ${ }^{66}$

Hepatitis C: The hepatitis $\mathrm{C}$ virus (HCV) replication involves the LDL receptor and enzymes involved in cholesterol biosynthesis. HCV viral replication may be interrupted by statins. Studies have revealed that statin use is linked to improvements in viral response to HCV treatments. ${ }^{67}$

NAFLD and NASH: Approximately 9 to $37 \%$ of people worldwide have non-alcoholic fatty liver disease (NAFLD), and 3 to $5 \%$ have nonalcoholic steatohepatitis (NASH), with greater occurrence in obesity patients. ${ }^{66}$ Statin use in these patients is associated with a decrease in transaminase levels, with improvements in steatosis and the liver necroinflammatory grade. However, no change in the grade of liver fibrosis was observed. ${ }^{68,69}$

Cognition: Few studies did not show relationship between statin therapy and cognitive impairment. ${ }^{70}$ The PROSPER ${ }^{71}$ and $\mathrm{HPS}^{72}$ studies have prospectively analyzed cognitive function and showed no association of statin therapy on cognitive function during the trial. ${ }^{73}$

Hemorrhagic stroke: The CTT meta-analysis demonstrated that treatment with statins will decrease the overall risk of stroke and ischemic stroke by $16 \%$ and $21 \%$ per $1 \mathrm{mmol} / \mathrm{L}$ reduction in LDL-C levels. ${ }^{10} \mathrm{~A}$ meta-analysis reported no association between statin therapy and increased risk of intracerebral stroke. $^{74}$

SPARCL trial (Stroke Prevention by Aggressive Reduction in Cholesterol Levels $)^{75}$ showed a significant increase in hemorrhagic stroke with atorvastatin. Therefore, any potential risk of hemorrhagic stroke is outweighed by the greater decline seen in overall stroke and major cardiovascular events.

\section{Conclusions}

Primary and secondary prevention trials of CVD have been grossly underpowered regarding enrolment of women, limiting the ability to stratify results by sex. Statins are safe and well tolerated in both the genders, but all patients cannot use statins. SAMS are the most common adverse effects in statin intolerance. Statins reduce coronary events and stroke in high-risk women. Benefits and risks of statin therapy in women for primary prevention remain less well defined than in men. CVD prevention includes lifestyle modification for all women and medical treatment for those with prevailing CVD risk factors or known disease. It has been proved that statins reduce the rates of cardiovascular events and mortality. RCTs showed that statins are safe in most of the patients with the previous history of stroke. In populations at high baseline risk of CVD, cardiovascular benefits of statin therapy overweigh the potential risk of increased serum glucose levels. 
By considering the safety concerns and significance to women, statins should be targeted to women at high-risk and must be avoided in low-risk group women with respect to CVD.

\section{Conflicts of Interest}

None.

\section{Acknowledgments}

None.

\section{References}

1 Centers for Disease Control and Prevention, https://www.cdc. gov/women/lcod/2015/race-ethnicity/index.htm. Accessed 06 May 2019

2 Katsiki N, Mikhailidis DP, Banach M. Effects of statin treatment on endothelial function, oxidative stress and inflammation in patients with arterial hypertension and normal cholesterol levels. J Hypertens 2011;29(12):2493-2494, author reply 2494

3 Raju SB, Varghese K, Madhu K. Management of statin intolerance. Indian J Endocrinol Metab 2013;17(6):977-982

4 Bosomworth NJ. Approach to identifying and managing atherogenic dyslipidemia: a metabolic consequence of obesity and diabetes. Can Fam Physician 2013;59(11):1169-1180

5 Banach M, Mikhailidis DP, Kjeldsen SE, Rysz J. Time for new indications for statins? Med Sci Monit 2009;15(12):MS1-MS5

6 Ford ES, Ajani UA, Croft JB, et al. Explaining the decrease in U.S. deaths from coronary disease, 1980-2000. N Engl J Med 2007;356(23):2388-2398

7 Stone NJ, Robinson JG, Lichtenstein AH, et al. American College of Cardiology/American Heart Association Task Force on Practice Guidelines. 2013 ACC/AHA guideline on the treatment of blood cholesterol to reduce atherosclerotic cardiovascular risk in adults: a report of the American College of Cardiology/ American Heart Association Task Force on Practice Guidelines. J Am Coll Cardiol 2014;63(25 Pt B):2889-2934

8 Hobbs FD, Banach M, Mikhailidis DP, Malhotra A, Capewell S. Is statin-modified reduction in lipids the most important preventive therapy for cardiovascular disease? A pro/con debate. BMC Med 2016;14:4

9 Colantonio LD, Bittner V, Reynolds K, et al. Association of serum lipids and coronary heart disease in contemporary observational studies. Circulation 2016;133(3):256-264

10 Baigent C, Blackwell L, Emberson J, et al. Cholesterol Treatment Trialists' (CTT) Collaboration. Efficacy and safety of more intensive lowering of LDL cholesterol: a meta-analysis of data from 170,000 participants in 26 randomised trials. Lancet 2010;376(9753):1670-1681

11 Baigent C, Keech A, Kearney PM, et al. Cholesterol Treatment Trialists' (CTT) Collaborators. Efficacy and safety of cholesterol-lowering treatment: prospective meta-analysis of data from 90,056 participants in 14 randomised trials of statins. Lancet 2005;366(9493):1267-1278

12 Muntean DM, Thompson PD, Catapano AL, et al. Statin-associated myopathy and the quest for biomarkers: can we effectively predict statin-associated muscle symptoms? Drug Discov Today 2017;22(1):85-96

13 Gluba-Brzozka A, Franczyk B, Toth PP, Rysz J, Banach M. Molecular mechanisms of statin intolerance. Arch Med Sci 2016;12(3):645-658

14 Banach M, Serban MC. Discussion around statin discontinuation in older adults and patients with wasting diseases. J Cachexia Sarcopenia Muscle 2016;7(4):396-399

15 Jackevicius CA, Mamdani M, Tu JV. Adherence with statin therapy in elderly patients with and without acute coronary syndromes. JAMA 2002;288(4):462-467
16 Serban MC, Colantonio LD, Manthripragada AD, et al. Statin intolerance and risk of coronary heart events and all-cause mortality following myocardial infarction. J Am Coll Cardiol 2017;69(11):1386-1395

17 Gutierrez J, Ramirez G, Rundek T, Sacco RL. Statin therapy in the prevention of recurrent cardiovascular events: a sex-based meta-analysis. Arch Intern Med 2012;172(12):909-919

182013 Prevention Guidelines Tools: CV Risk Calculator http:// my.americanheart.org/professional/StatementsGuidelines/ PreventionGuidelines/Prevention-Guidelines_UCM_457698_ SubHomePage.jsp. Accessed May 4, 2019

19 Monsuez JJ, Pham T, Karam N, et al. Awareness of individual cardiovascular risk factors and self-perception of cardiovascular risk in women. Am. J Med Sci 2017;354(3):240-245

20 Mosca L, Benjamin EJ, Berra K, et al. Effectiveness-based guidelines for the prevention of cardiovascular disease in women-2011 update: a guideline from the American Heart Association. Circulation 2011;123(11):1243-1262

21 Devaraj S, Siegel D, Jialal I. Statin therapy in metabolic syndrome and hypertension post-JUPITER: what is the value of CRP? Curr Atheroscler Rep 2011;13(1):31-42

22 Singh D, Lippmann S. Can statins diminish depression? Prim Care Companion CNS Disord 2018;20(1):17

23 Ortega I, Duleba AJ, Role of statins in PCOS management. In Pal L, ed Polycystic Ovary Syndrome. New York, NY: Springer; 2014 181-203

24 Schooling CM, Au Yeung SL, Freeman G, Cowling BJ. The effect of statins on testosterone in men and women, a systematic review and meta-analysis of randomized controlled trials. BMC Med 2013;11:57

25 Kostis WJ, Cheng JQ Dobrzynski JM, Cabrera J, Kostis JB. Meta-analysis of statin effects in women versus men. J Am Coll Cardiol 2012;59(6):572-582

26 Ridker PM, Danielson E, Fonseca FA, et al. JUPITER Study Group. Rosuvastatin to prevent vascular events in men and women with elevated C-reactive protein. N Engl J Med 2008;359(21):2195-2207

27 Zhang H, Plutzky J, Skentzos S, et al. Discontinuation of statins in routine care settings: a cohort study. Ann Intern Med 2013;158(7):526-534

28 Preiss D, Seshasai SR, Welsh P, et al. Risk of incident diabetes with intensive-dose compared with moderate-dose statin therapy: a meta-analysis. JAMA 2011;305(24):2556-2564

29 Stancu C, Sima A. Statins: mechanism of action and effects. J Cell Mol Med 2001;5(4):378-387

30 Stone NJ, Robinson JG, Lichtenstein AH, et al. American College of Cardiology/American Heart Association Task Force on Practice Guidelines. 2013 ACC/AHA guideline on the treatment of blood cholesterol to reduce atherosclerotic cardiovascular risk in adults: a report of the American College of Cardiology/ American Heart Association Task Force on Practice Guidelines. Circulation 2014; 129(25, Suppl 2):S1-S45

31 Rader DJ. New therapeutic approaches to the treatment of dyslipidemia. Cell Metab 2016;23(3):405-412

32 Davies JT, Delfino SF, Feinberg CE, et al. Current and emerging uses of statins in clinical therapeutics: a review. Lipid Insights 2016;9:13-29

33 Lewis SF, Hennekens $\mathrm{CH}$. Regular physical activity: forgotten benefits. Am J Med 2016;129(2):137-138

34 Fulcher J, O'Connell R, Voysey M, et al. Cholesterol Treatment Trialists' (CTT) Collaboration. Efficacy and safety of LDL-lowering therapy among men and women: meta-analysis of individual data from 174,000 participants in 27 randomised trials. Lancet 2015;385(9976):1397-1405

35 Ridker PM, MacFadyen JG, Fonseca FA, et al. JUPITER Study Group. Number needed to treat with rosuvastatin to prevent first cardiovascular events and death among men and 
women with low low-density lipoprotein cholesterol and elevated high-sensitivity C-reactive protein: justification for the use of statins in prevention: an intervention trial evaluating rosuvastatin (JUPITER) Circ Cardiovasc Qual Outcomes 2009;2(6):616-623

36 Ridker PM, Pradhan A, MacFadyen JG, Libby P, Glynn RJ. Cardiovascular benefits and diabetes risks of statin therapy in primary prevention: an analysis from the JUPITER trial. Lancet 2012;380(9841):565-571

37 Authors/Task Force, Members: Catapano AL, Graham I, De Backer G, et al. 2016 ESC/EAS guidelines for the management of dyslipidaemias: The task force for the management of dyslipidaemias of the European Society of Cardiology (ESC) and European Atherosclerosis Society (EAS) developed with the special contribution of: European Association for Cardiovascular Prevention \& Rehabilitation (EACPR). Atherosclerosis 2016;253:281-344

38 Banach M, Mikhailidis DP. Statin therapy and new-onset diabetes: an attempt at recommendations. Expert Rev Endocrinol Metab 2013;8(3):213-216

39 Mora S, Glynn RJ, Hsia J, MacFadyen JG, Genest J, Ridker PM. Statins for the primary prevention of cardiovascular events in women with elevated high-sensitivity C-reactive protein or dyslipidemia: results from the Justification for the Use of Statins in Prevention: An Intervention Trial Evaluating Rosuvastatin (JUPITER) and meta-analysis of women from primary prevention trials. Circulation 2010;121(9):1069-1077

40 Bukkapatnam RN, Gabler NB, Lewis WR. Statins for primary prevention of cardiovascular mortality in women: a systematic review and meta-analysis. Prev Cardiol 2010;13(2):84-90

41 Kostis WJ, Cheng JQ Dobrzynski JM, Cabrera J, Kostis JB. Meta-analysis of statin effects in women versus men. J Am Coll Cardiol 2012;59(6):572-582

42 Hennekens $\mathrm{CH}$, Lieberman EH, Rubenstein MH, Hebert PR, DeMets DL, Pfeffer MA. Statins in the treatment and prevention of cardiovascular diseases: current and emerging clinical and public health challenges. In: Handbook of Cholesterol. The Netherlands: Wageningen Academic Publishers; 2016:155-180

43 Truong QA, Murphy SA, McCabe CH, Armani A, Cannon CP; TIMI Study Group. Benefit of intensive statin therapy in women: results from PROVE IT-TIMI 22. Circ Cardiovasc Qual Outcomes 2011;4(3):328-336

44 Bruckert E, Hayem G, Dejager S, Yau C, Bégaud B. Mild to moderate muscular symptoms with high-dosage statin therapy in hyperlipidemic patients-the PRIMO study. Cardiovasc Drugs Ther 2005;19(6):403-414

45 Cohen JD, Brinton EA, Ito MK, Jacobson TA. Understanding Statin Use in America and Gaps in Patient Education (USAGE): an internet-based survey of 10,138 current and former statin users. J Clin Lipidol 2012;6(3):208-215

46 Colantonio LD, Huang L, Monda KL, et al. Adherence to high-intensity statins following a myocardial infarction hospitalization among medicare beneficiaries. JAMA Cardiol 2017;2(8):890-895

47 Rosenson RS, Baker SK, Jacobson TA, Kopecky SL, Parker BA; The National Lipid Association's Muscle Safety Expert Panel. An assessment by the Statin Muscle Safety Task Force: 2014 update. J Clin Lipidol 2014; 8(3, Suppl):S58-S71

48 Parker BA, Capizzi JA, Grimaldi AS, et al. Effect of statins on skeletal muscle function. Circulation 2013;127(1):96-103

49 Schech S, Graham D, Staffa J, et al. Risk factors for statinassociated rhabdomyolysis. Pharmacoepidemiol Drug Saf 2007;16(3):352-358

50 Abd TT, Jacobson TA. Statin-induced myopathy: a review and update. Expert Opin Drug Saf 2011;10(3):373-387

51 Guengerich FP. Cytochrome p450 and chemical toxicology. Chem Res Toxicol 2008;21(1):70-83
52 Gupta A, Thompson D, Whitehouse A, et al. ASCOT Investigators. Adverse events associated with unblinded, but not with blinded, statin therapy in the Anglo-Scandinavian Cardiac Outcomes Trial-Lipid-Lowering Arm (ASCOT-LLA): a randomised double-blind placebo-controlled trial and its non-randomised non-blind extension phase. Lancet 2017;389(10088):2473-2481

53 Sever PS, Dahlöf B, Poulter NR, et al. ASCOT investigators. Prevention of coronary and stroke events with atorvastatin in hypertensive patients who have average or lower-than-average cholesterol concentrations, in the Anglo-Scandinavian Cardiac Outcomes Trial-Lipid Lowering Arm (ASCOT-LLA): a multicentre randomised controlled trial. Lancet 2003;361 (9364):1149-1158

54 Guyton JR, Bays HE, Grundy SM, Jacobson TA; The National Lipid Association Statin Intolerance Panel. An assessment by the Statin Intolerance Panel: 2014 update. J Clin Lipidol 2014; 8(3, Suppl):S72-S81

55 Banach M, Rizzo M, Toth PP, et al. Statin intolerance-an attempt at a unified definition. Position paper from an International Lipid Expert Panel. Arch Med Sci 2015;11(1):1-23

56 Adhyaru BB, Jacobson TA. Safety and efficacy of statin therapy. Nat Rev Cardiol 2018;15(12):757-769

57 Cannon CP, Blazing MA, Giugliano RP, et al. IMPROVE-IT Investigators. Ezetimibe added to statin therapy after acute coronary syndromes. N Engl J Med 2015;372(25):2387-2397

58 Nissen SE, Stroes E, Dent-Acosta RE, et al. Efficacy and tolerability of evolocumab vs ezetimibe in patients with musclerelated statin intolerance: the GAUSS-3 randomized clinical trial. JAMA 2016;315(15):1580-1590

59 Moriarty PM, Jacobson TA, Bruckert E, et al. Efficacy and safety of alirocumab, a monoclonal antibody to PCSK9, in statin-intolerant patients: design and rationale of ODYSSEY ALTERNATIVE, a randomized phase 3 trial. J Clin Lipidol 2014;8(6):554-561

60 Orringer CE, Jacobson TA, Saseen JJ, et al. Update on the use of PCSK9 inhibitors in adults: recommendations from an Expert Panel of the National Lipid Association. J Clin Lipidol 2017;11(4):880-890

61 LaRosa JC, Grundy SM, Waters DD, et al. Treating to New Targets (TNT) Investigators. Intensive lipid lowering with atorvastatin in patients with stable coronary disease. N Engl J Med 2005;352(14):1425-1435

62 Pedersen TR, Faergeman O, Kastelein JJ, et al. Incremental Decrease in End Points Through Aggressive Lipid Lowering (IDEAL) Study Group. High-dose atorvastatin vs usual-dose simvastatin for secondary prevention after myocardial infarction: the IDEAL study: a randomized controlled trial. JAMA 2005;294(19):2437-2445

63 Cannon CP, Braunwald E, McCabe $\mathrm{CH}$, et al. Pravastatin or Atorvastatin Evaluation and Infection Therapy-Thrombolysis in Myocardial Infarction 22 Investigators. Intensive versus moderate lipid lowering with statins after acute coronary syndromes. N Engl J Med 2004;350(15):1495-1504

64 de Lemos JA, Blazing MA, Wiviott SD, et al. Investigators. Early intensive vs a delayed conservative simvastatin strategy in patients with acute coronary syndromes: phase $\mathrm{Z}$ of the $\mathrm{A}$ to $\mathrm{Z}$ trial. JAMA 2004;292(11):1307-1316

65 Armitage J, Bowman L, Wallendszus K, et al. Study of the Effectiveness of Additional Reductions in Cholesterol and Homocysteine (SEARCH) Collaborative Group. Intensive lowering of LDL cholesterol with $80 \mathrm{mg}$ versus $20 \mathrm{mg}$ simvastatin daily in 12,064 survivors of myocardial infarction: a double-blind randomised trial. Lancet 2010;376(9753):1658-1669

66 Bays H, Cohen DE, Chalasani N, Harrison SA; The National Lipid Association's Statin Safety Task Force. An assessment by the Statin Liver Safety Task Force: 2014 update. J Clin Lipidol 2014;8(3. Suppl):S47-S57 
67 Henderson LM, Patel S, Giordano TP, Green L, El-Serag HB. Statin therapy and serum transaminases among a cohort of HCV-infected veterans. Dig Dis Sci 2010;55(1):190-195

68 Gómez-Domínguez E, Gisbert JP, Moreno-Monteagudo JA, García-Buey L, Moreno-Otero R. A pilot study of atorvastatin treatment in dyslipemid, non-alcoholic fatty liver patients. Aliment Pharmacol Ther 2006;23(11):1643-1647

69 Hyogo H, Tazuma S, Arihiro K, et al. Efficacy of atorvastatin for the treatment of nonalcoholic steatohepatitis with dyslipidemia. Metabolism 2008;57(12):1711-1718

70 Ott BR, Daiello LA, Dahabreh IJ, et al. Do statins impair cognition? A systematic review and meta-analysis of randomized controlled trials. J Gen Intern Med 2015;30(3):348-358

71 Shepherd J, Blauw GJ, Murphy MB, et al. PROSPER study group. PROspective Study of Pravastatin in the Elderly at Risk. Pravastatin in elderly individuals at risk of vascular disease (PROSPER): a randomised controlled trial. Lancet 2002;360(9346):1623-1630
72 Heart Protection Study Collaborative Group. MRC/BHF Heart Protection Study of antioxidant vitamin supplementation in 20,536 high-risk individuals: a randomised placebo-controlled trial. Lancet 2002;360(9326):23-33

73 Trompet S, van Vliet P, de Craen AJ, et al. Pravastatin and cognitive function in the elderly. Results of the PROSPER study. J Neurol 2010;257(1):85-90

74 Hackam DG, Woodward M, Newby LK, et al. Statins and intracerebral hemorrhage: collaborative systematic review and meta-analysis. Circulation 2011;124(20):2233-2242

75 Amarenco P, Bogousslavsky J, Callahan A, III, et al; Stroke Prevention by Aggressive Reduction in Cholesterol Levels (SPARCL) Investigators, et al. High-dose atorvastatin after stroke or transient ischemic attack. N Engl J Med 2006;355(6):549-559 